Special Issue of the 8th International Advances in Applied Physics and Materials Science Congress (APMAS 2018)

\title{
Slot-Die Coated Active Carbon Films for Hydrogen Storage Applications
}

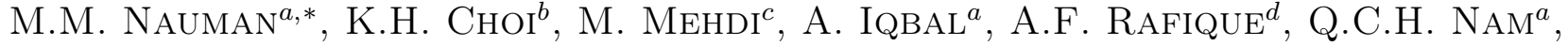 \\ J.H. ZAINI ${ }^{a}$ AND M. IQBAL ${ }^{a}$ \\ ${ }^{a}$ Universiti Brunei Darussalam, Faculty of Integrated Technologies, Bandar Seri Begawan, Brunei Darussalam \\ ${ }^{b}$ Jeju National University, Department of Mechatronics Engineering, Jeju, South Korea \\ ${ }^{c}$ NED University of Engineering and Technology, Department of Mechanical Engineering, Karachi, Pakistan \\ ${ }^{d}$ King Abdulaziz University, Department of Aeronautical Engineering, Jeddah, Saudi Arabia
}

\begin{abstract}
Slot-die technique for the deposition of $\approx 3 \mu \mathrm{m}$, ultra-pure active carbon layers has been discussed in this paper with their potential use in hydrogen storage applications. Activated carbon nanoparticle inks were manufactured for their use in the process for the deposition of layers on flexible PET substrates whereby the roll-to-roll system provided the continuous feed of the flexible substrate. Different parameters affecting the process and the deposited layer thickness and uniformity such as stand-off distance, flow rate, and substrate speed have been examined through CFD simulations to come up with an optimized parameter combination. Layers with fine uniformity are achieved and an operating envelope is constructed between the applicable values of coating speed and flow rate. Flow rate below $0.9 \mathrm{ml} / \mathrm{h}$ and more than $1.75 \mathrm{ml} / \mathrm{h}$ was deemed unfit for the process. Based on these values the substrate speed of $70-100 \mathrm{~mm} / \mathrm{s}$ is determined to be the recommended speed. The thickness of the deposited films varied from $3 \mu \mathrm{m}$ to $8 \mu \mathrm{m}$ with varying flow rate and varying stand-off distance. The cost-effectiveness, room-temperature operation, environment friendliness, and simplicity of the process with its possible integration with high throughout manufacturing processes like roll-to-roll process makes it an idyllic candidate for deployment in the challenging field of hydrogen storage at a large scale.
\end{abstract}

DOI: 10.12693/APhysPolA.135.705

PACS/topics: active carbon, hydrogen storage, slot-die coating, thin films, characterization

\section{Introduction}

Hydrogen is an appropriate alternative to conventional fuels because of its natural abundance and high energy density or heating value per unit mass as well as being environmentally friendly. Widespread uptake of hydrogen energy has yet not occurred because of difficulties with its storage since the gas has low energy density per unit volume requiring a large storage space at ambient conditions. Methods to address this problem include hydrogen compression at high pressures (700 bar) or storing in liquid form at cryogenic temperatures (20 K) [1]. However, these techniques have associated drawbacks such as manufacturing of cylinders capable of withstanding ultrahigh pressures (up to $70 \mathrm{MPa}$ ) with light weight, energy consuming process for both gaseous hydrogen compression and liquefaction, permeation and safety issues. Physisorption process is thought to be as the alternative way in physical hydrogen storage routes that absorb hydrogen in highly porous solid-state adsorbents such as nanoporous carbon and metal organic frameworks (MOFs). However, significant hydrogen adsorptive storage capacities in physisorption need to be reached at liquid nitrogen temperatures $(77 \mathrm{~K})$ and pressures of sev-

*corresponding author; e-mail: malik.nauman@ubd.edu.bn eral MPa. This is attributed to weak binding energy between molecular hydrogen and the surface of sorbents in the range of $\left.2-5 \mathrm{~kJ} /(\mathrm{mol} \mathrm{H})_{2}\right)$. Generally, the hydrogen storage properties of physisorption are limited by specific surface area, pore structures and pore size distributions, surface functionality and the bulk density of the adsorbent [2].

Hydrides of some metals and non-metals form a different class of materials for hydrogen storage characterized by their ability to store larger amounts of $\mathrm{H}_{2}$ through the formation of chemical bonds. For instance, metal hydrides for hydrogen storage starts with dissociation of hydrogen molecules, migration and chemical bonding of the hydrogen atoms by integration in the lattice of metals with a high binding energy $\left(>50 \mathrm{~kJ} /\left(\mathrm{mol} \mathrm{H}_{2}\right)\right)$, therefore storage capacities and the operating temperatures are elevated. However, the main shortcoming in chemisorption is usually the requirement of high temperatures to absorb/release the hydrogen due to high binding energy. Hydrogen's low energy-density makes it difficult to store enough on board of a vehicle to achieve sufficient vehicle distance range without the storage container being too large or too heavy. Most promising existing and proposed technologies for hydrogen storage include physical storage: pressurized tanks for gaseous hydrogen and pressurized cryotanks for liquid hydrogen [1]; reversible hydrogen uptake in various metal based compounds including hydrides, nitrides, and imides [3]; chemical storage in irreversible hydrogen carriers such as methanol [4]; cryoad- 
sorption with activated carbon as the most common adsorbent [5]; and advanced carbon materials absorption, including carbon nanotubes, alkali doped carbon nanotubes, and graphite nanofibers [6].

Printing of thin films of active carbon are relatively new research area and this research endeavours on this exciting field of research. At the moment rarely anyone is working on printing active carbon nanoparticle based thin films to validate the potential of hydrogen storage. A major issue that precludes breakthroughs in this research is making of homogeneous nanoparticle inks $[7,8]$ which will last during the whole printing process. Hence, this research can be considered as a stepping stone for further research in the field of thin film hydrogen storage devices which can a have huge application potential in low power electronics where miniature fuel cells can be utilized for powering the components and hydrogen can be stored in thin films of carbon deposited on flexible substrates. Some researchers have deposited active carbon thin films using different coating techniques. For example, Wei et al. has used lithography to deposit conductive, continuous, smooth, visibly defect-free, activated carbon films on the surface of hard silicon wafers for the manufacturing of functional electric double layer capacitor. They were able to tune the porosity and surface area by controlling the activation conditions [9]. Fathy et al. used the batch acid spraying technique to make transparent amorphous carbon thin films in the presence of cobalt silicate as a catalyst at low temperatures [10].

This study deals with an easy way to fabricate storage device which has active carbon films printed on a flexible PET substrate using the slot die coating process that is attached with a lab-scale continuous roll-to-roll process. Active carbon nanoparticle inks are first prepared and then simulations, based on the physical properties of inks and slot die coating head's physical dimensions, are carried out to first determine the optimized parameters for the coating process and then films are fabricated using such parameters. Finally, the films are characterized and an operating envelope is constructed for the optimized process execution.

\section{Ink synthesis}

Low density fluoropolymer, polyvinylidene fluoride (PVDF) purchased from Aldrich has been used as a dispersion media for the active carbon (AC) nanoparticles where AC:PVDF was kept at 9:1. N-methyl-2pyrrolidone (NMP) was used as a solvent. A recipe surfactant was also used for better dispersion, homogeneity and ink integrity. The final ink consisted of $15 \mathrm{wt} \%$ active carbon - PVDF content.

Dispersed AC nano particles were ultrasonicated for 5 min with pulsed signals at a frequency of $0.4 \mathrm{~kW}$ before mixing with PVDF and other components. The mixed solution was mechanically stirred and shaken at low speeds in a mechanical shaker for $36 \mathrm{~h}$. The stability of the ink has been investigated using Turbiscan MA 2000 and is presented in Fig. 1. It can be seen that ink has the excellent homogeneity where the transmission loss occurring at the lowest distance. The physical properties of the ink were measured by surface tension meter (SEO-Phoenix) and it came out to be $21 \mathrm{~N} / \mathrm{m}$. The measurement of viscosity was carried out with a staincontrolled viscometer (Sekonic Viscomate VM-10A) and was recorded as $\approx 20$ cps. The density of the ink was measured as $1160 \mathrm{~kg} / \mathrm{m}^{3}$.

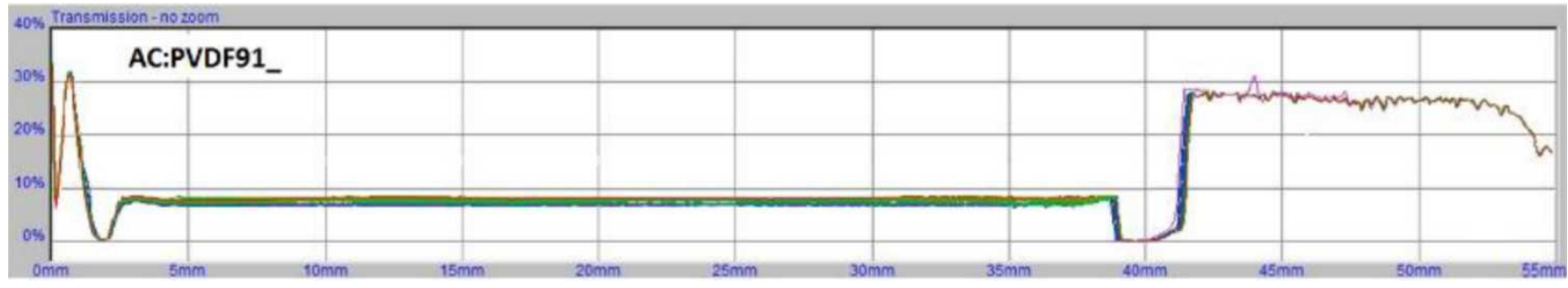

Fig. 1. Turbi-scans of all the AC ink showing good stability.

\section{Simulation details}

\subsection{Modelling}

The details of the roll-to-roll continuous slot-die manufacturing process can be found elsewhere $[11,12]$. Simplified two-dimensional (2D) simulations of the process were carried out to obtain the most suitable coating parameters as to achieve films with thickness of 3-8 $\mu \mathrm{m}$. Coating process was simulated at different coating speeds, flow rates and offset distance i.e. nozzle to substrate distance. The simplified model used in the simulations along with the boundary conditions is given in Fig. 2 and the operating parameters are given in Table I.
TABLE I

Simulation parameters

\begin{tabular}{l|l}
\hline \hline \multicolumn{1}{c|}{ Parameters } & \multicolumn{1}{c}{ Values } \\
\hline ink model & homogeneous viscous liquid \\
viscosity & $20 \mathrm{cps}$ \\
ink density & $1160 \mathrm{~kg} / \mathrm{m}^{3}$ \\
nozzle-substrate clearance & constant $=80 \mu \mathrm{m}$ \\
flow-rate $Q$ & varying from $30-100 \mathrm{ml} / \mathrm{h}$ \\
substrate speed $v$ & varying from $0.9-1.75 \mathrm{~mm} / \mathrm{s}$
\end{tabular}




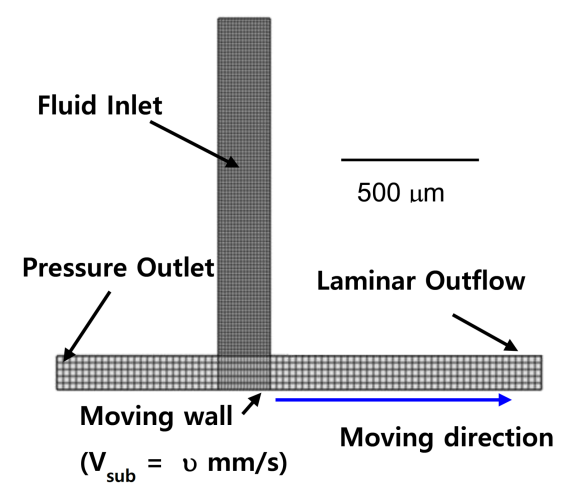

Fig. 2. Simulation model with boundary conditions.

\section{Simulation results}

\subsection{Substrate speed variation}

Simulations were carried out at constant flow rate of $0.9 \mu \mathrm{l} / \mathrm{h}$ while varying the substrate speed. Simulation results for the substrate speed of $30 \mathrm{~mm} / \mathrm{s}$ are shown in Fig. 3. It is observed that at the start, the bead breakup phenomenon is observed. A lump of mass is gradually accumulated on the substrate due to the slow speed of the substrate. This lump is carried out by the moving substrate. A very thick film is deposited as a result and the process is not uniform.

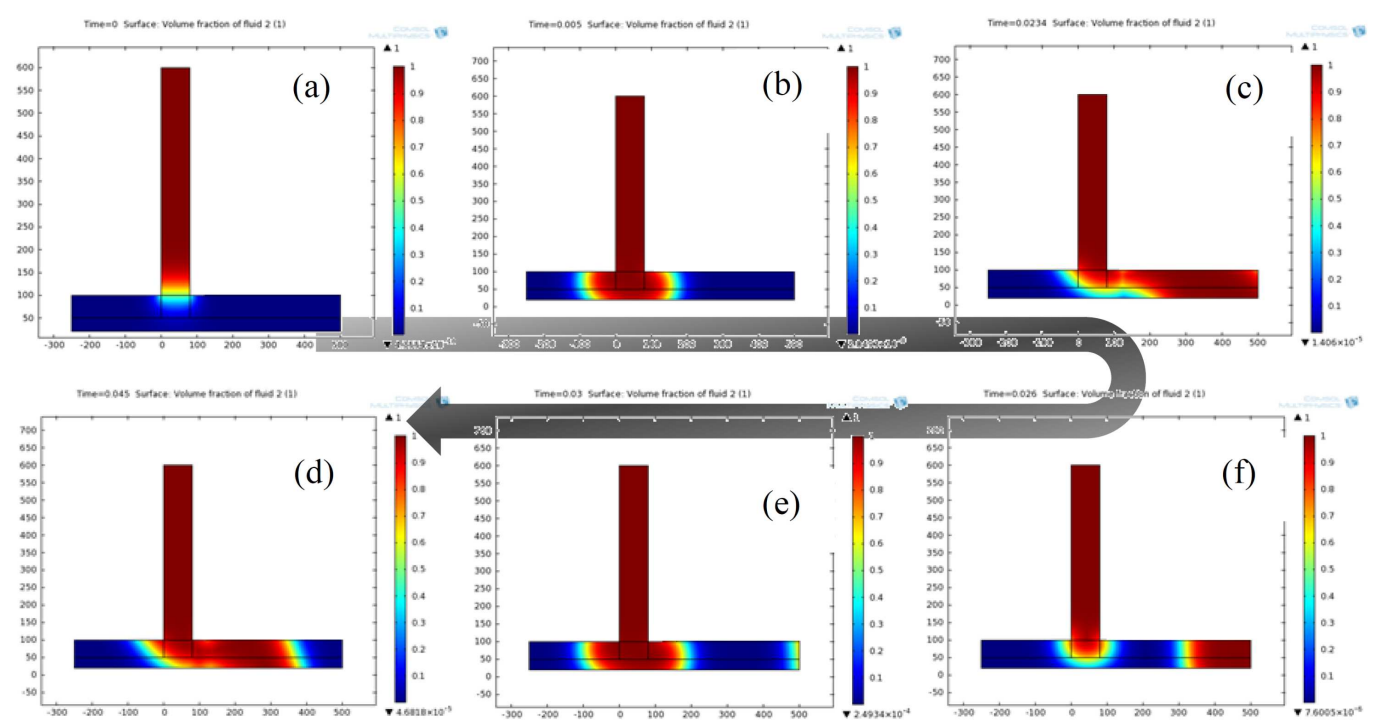

Fig. 3. (a-f) Simulation results at $v=30 \mathrm{~mm} / \mathrm{s}$ at different times where $0 \leq t \leq 0.045 \mathrm{~s}$.

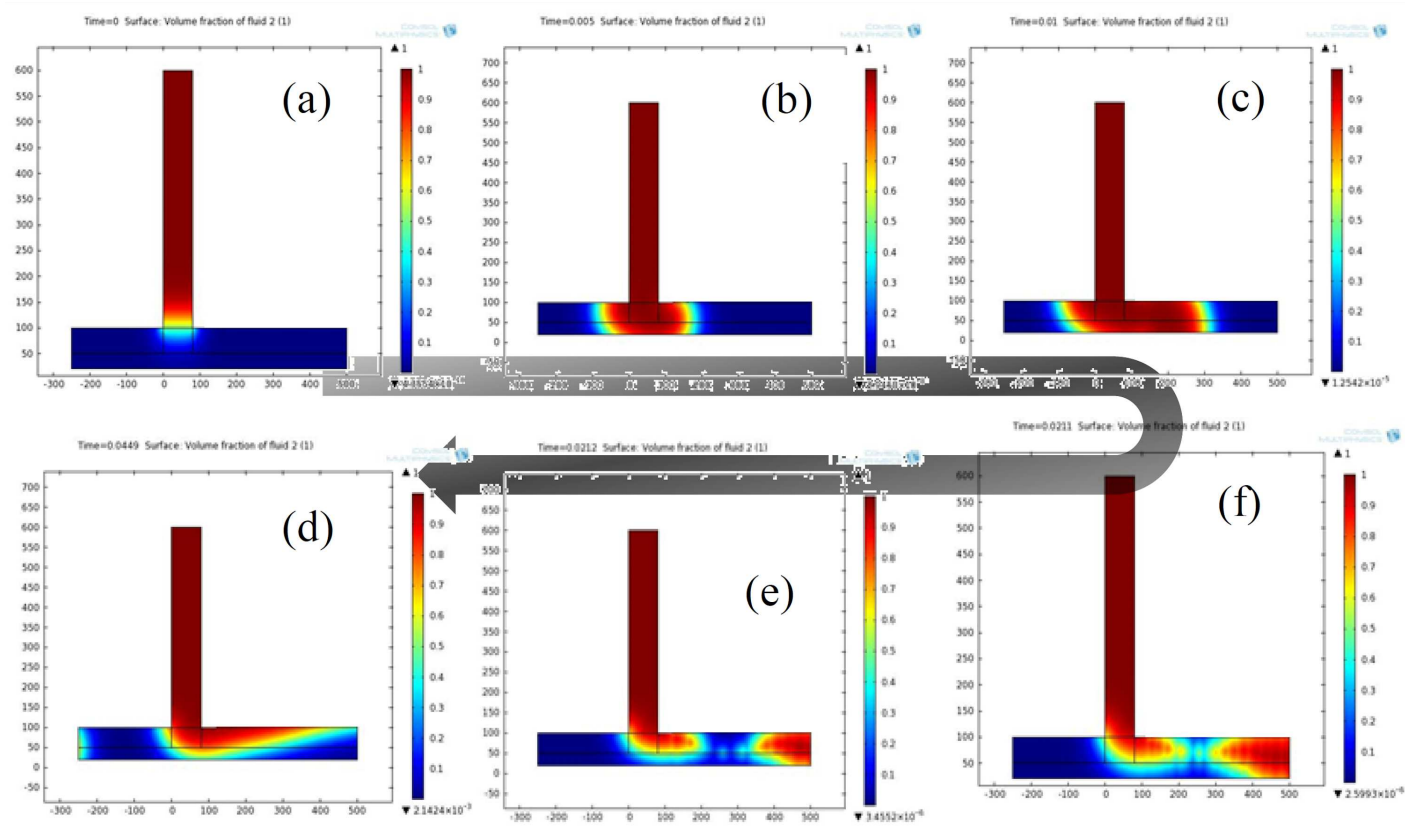

Fig. 4. (a-f) Simulation results at $v=50 \mathrm{~mm} / \mathrm{s}$ at different times where $0 \leq t \leq 0.045 \mathrm{~s}$. 


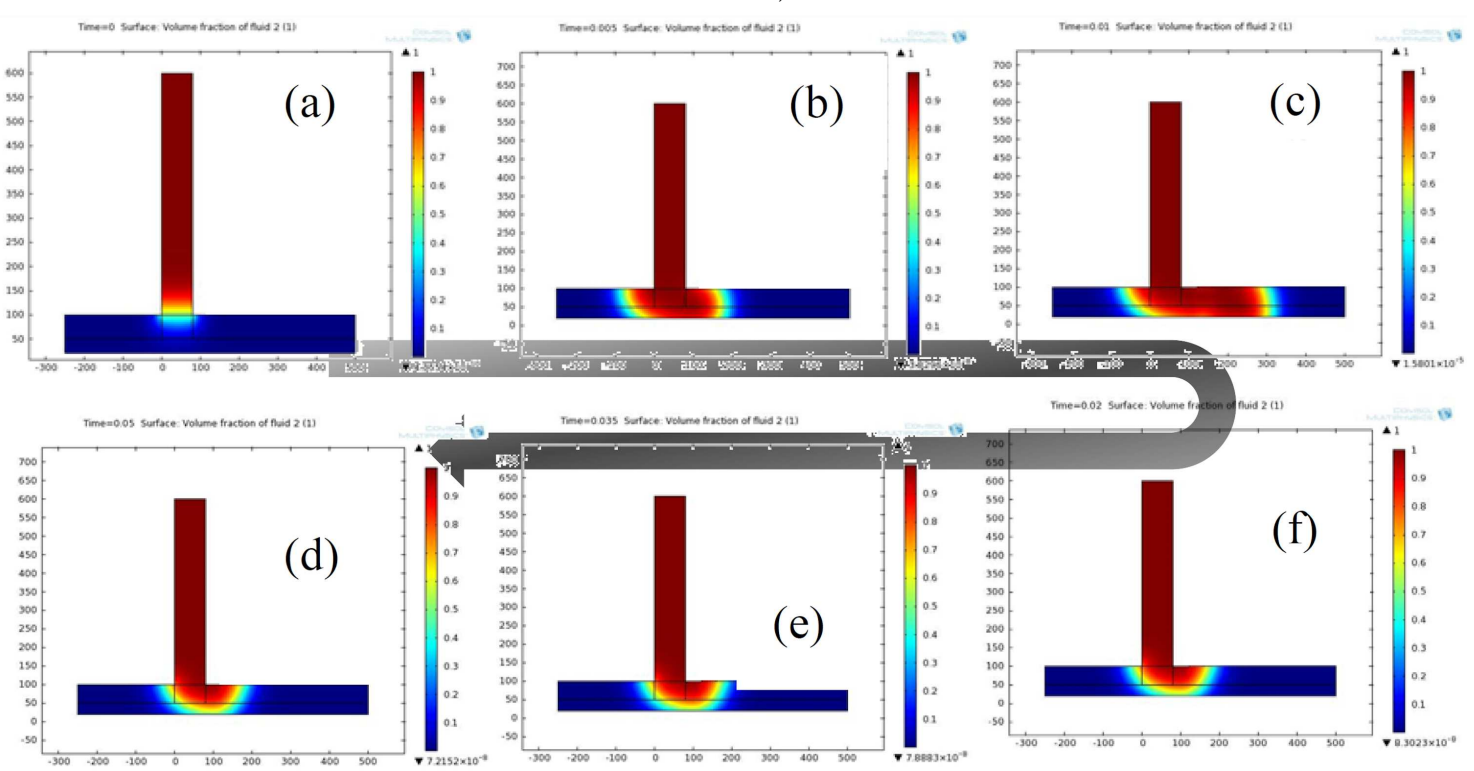

Fig. 5. (a-f) Simulation results at $v=75 \mathrm{~mm} / \mathrm{s}$ at different times where $0 \leq t \leq 0.05 \mathrm{~s}$.

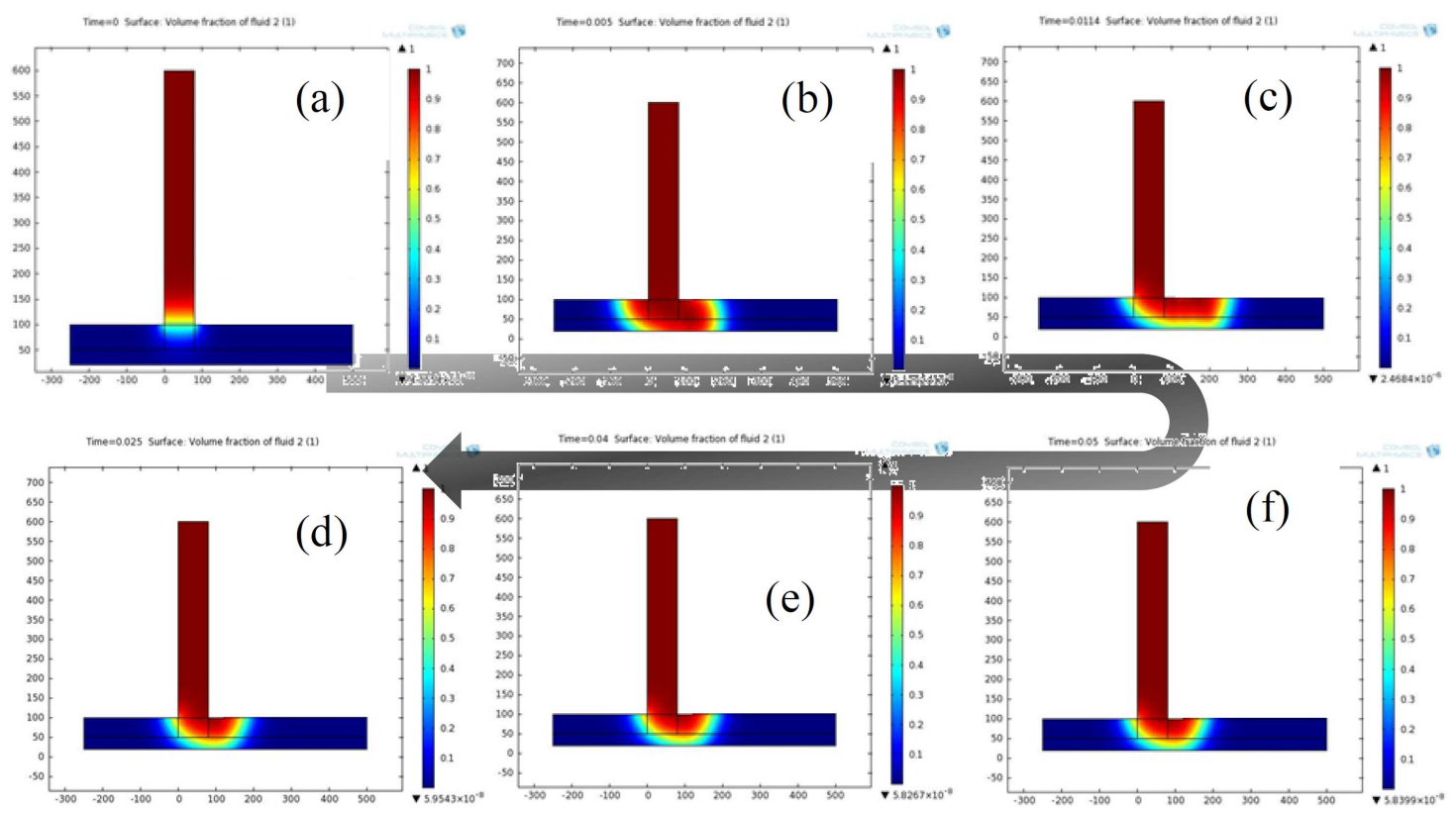

Fig. 6. (a-f) Simulation results at $v=100 \mathrm{~mm} / \mathrm{s}$ at different times where $0 \leq t \leq 0.025 \mathrm{~s}$.

Simulation results for the substrate speed of $50 \mathrm{~mm} / \mathrm{s}$ are shown in Fig. 4. In the start, the bead breakup phenomenon is observed at this speed as well. However, the process is much stable as compared to the previous case. Estimated film thickness is around $20 \mu \mathrm{m}$ in this case. Film thickness is the estimated by the interface thickness (distance from the substrate to the end of light blue region) [13]. Some instability is also experienced in this case which is visible in the left corner. Simulation results for the substrate speed of $75 \mathrm{~mm} / \mathrm{s}$ are shown in Fig. 5. No bead breakup phenomenon is observed in this case. The process is very stable as com- pared to the previous cases. Estimated film thickness is $\approx 10 \mu \mathrm{m}$ in this case. No instabilities are experienced in this case. This substrate speed is the recommended one for the respective operating parameters. Simulation results for the substrate speed of $100 \mathrm{~mm} / \mathrm{s}$ are given in Fig. 6. No bead breakup phenomenon is observed in this case as well. The process is very stable. Estimated film thickness is $\approx 5 \mu \mathrm{m}$ in this case. No instabilities are experienced in this case as well. Therefore, a recommended range which can be concluded from this simulation study is $75-100 \mathrm{~mm} / \mathrm{s}$ for the respective operating parameters. 


\subsection{Flowrate variation}

Simulations were carried out at substrate speed of $100 \mathrm{~mm} / \mathrm{s}$ which was determined in the previous section. Flow rate was varied in this case. Simulation results for the flow rate of $1 \mathrm{ml} / \mathrm{h}$ are shown in Fig. 7. It is observed that the process is very stable. Estimated film thickness is $\approx 3 \mu \mathrm{m}$ in this case and no instabilities are experienced. These coating parameters define the mid-range of the stable operating envelope.

Simulation results for the flow rate of $1.25 \mathrm{ml} / \mathrm{h}$ are shown in Fig. 8. The process is quite stable at this flow rate as well. However, the estimated film thickness is $\approx 10 \mu \mathrm{m}$ in this case and no instabilities are experienced either. These coating parameters define the upper range of the stable operating envelope.
Simulation results for the flow rate of $1.5 \mathrm{ml} / \mathrm{h}$ are shown in Fig. 9. As expected, the process is not stable at this flow rate. Many instabilities occur before the process is stabilized for a short period and then again, the process becomes unstable. At the start, the bead breakup phenomenon is observed. The estimated film thickness is more than $25 \mu \mathrm{m}$ in this case. These coating parameters define the starting period of the unstable range of the operating envelope. Simulation results for the flow rate of $1.80 \mathrm{ml} / \mathrm{h}$ are given in Fig. 10. The process is very unstable throughout the simulation time. A lump of mass is gradually accumulated on the substrate because of the high flow rate of the substrate. This lump is carried out by the moving substrate. A very thick film is deposited as a result and the process is not uniform as well.

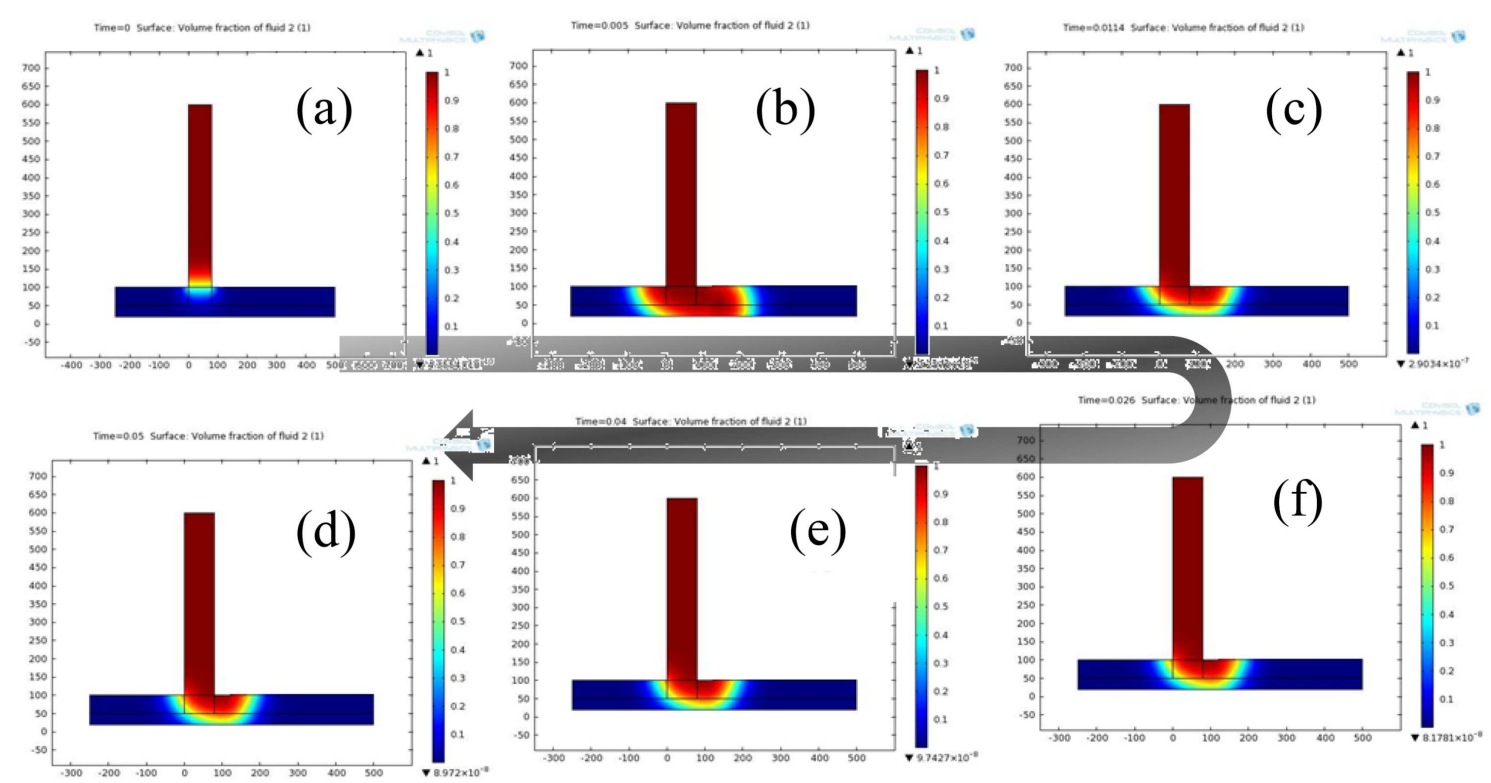

Fig. 7. (a-f) Simulation results at $Q=1 \mathrm{ml} / \mathrm{h}$ at different times where $0 \leq t \leq 0.05 \mathrm{~s}$.

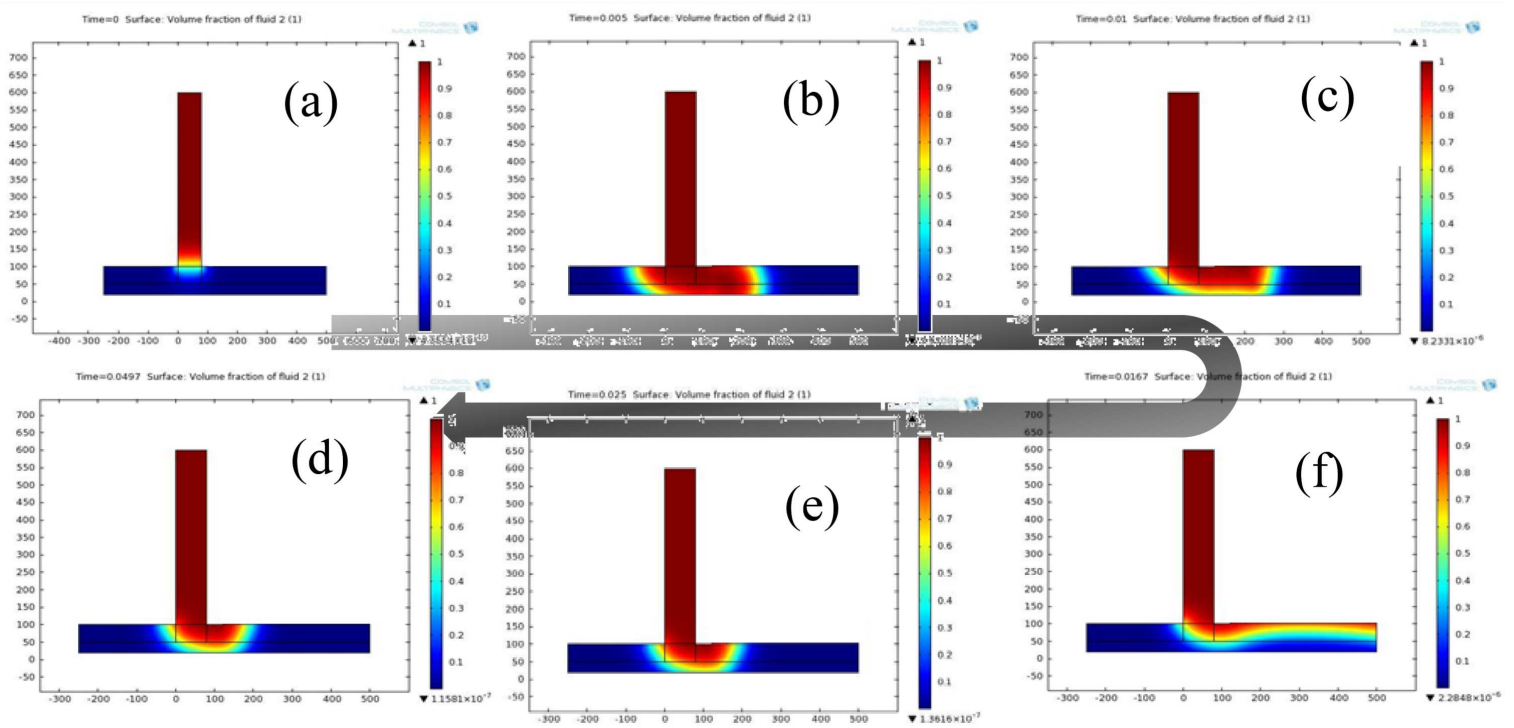

Fig. 8. (a-f) Simulation results at $Q=1.25 \mathrm{ml} / \mathrm{h}$ at different times where $0 \leq t \leq 0.045 \mathrm{~s}$. 


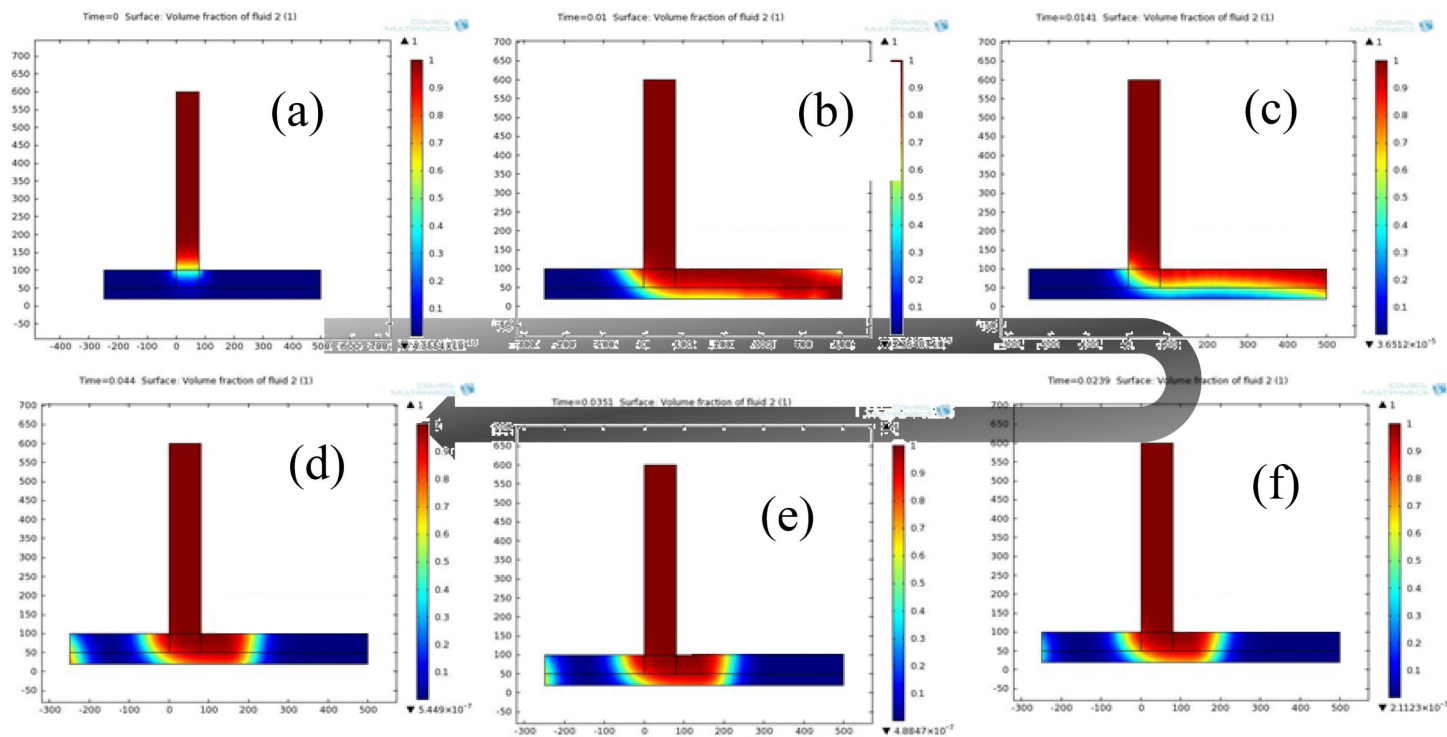

Fig. 9. (a-f) Simulation results at $Q=1.50 \mathrm{ml} / \mathrm{h}$ at different times where $0 \leq t \leq 0.045 \mathrm{~s}$.

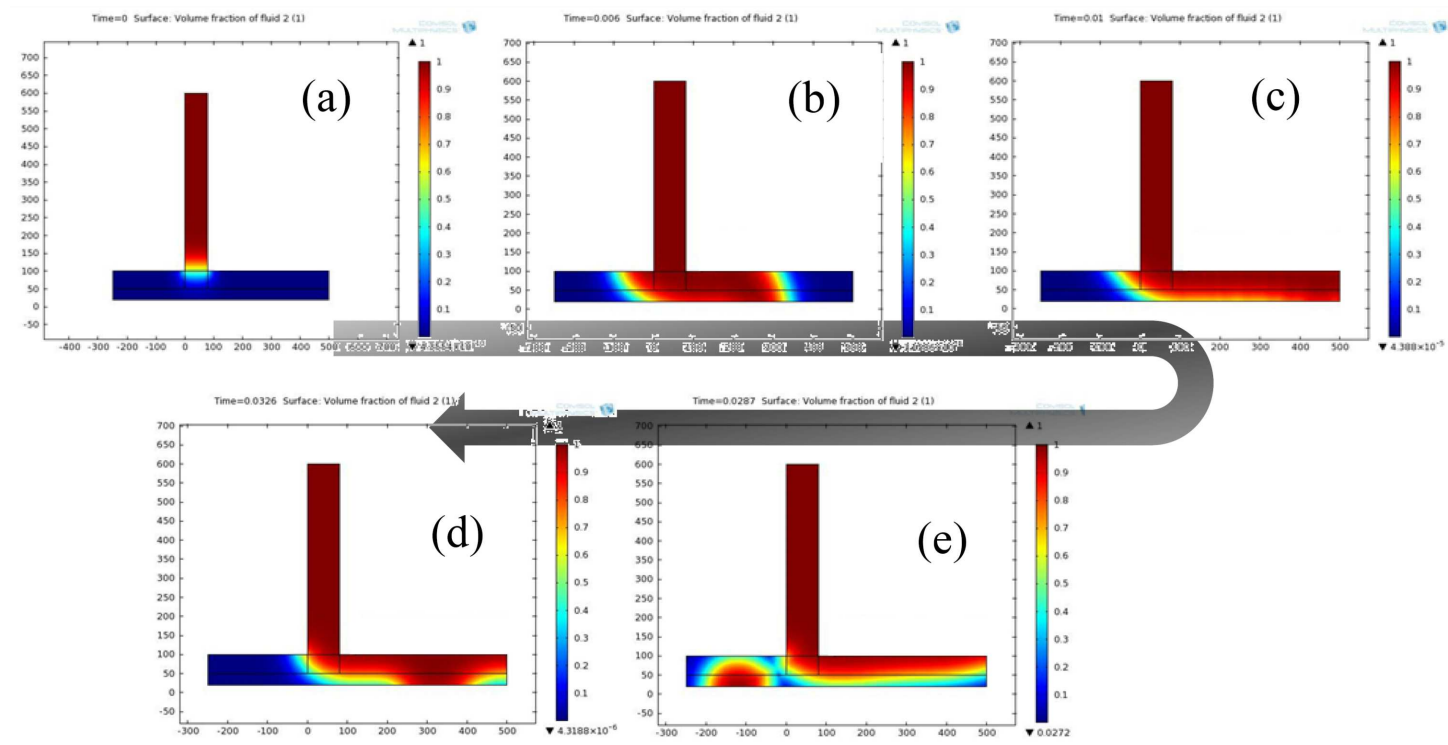

Fig. 10. (a-e) Simulation results at $Q=1.80 \mathrm{ml} / \mathrm{h}$ at different times where $0 \leq t \leq 0.032 \mathrm{~s}$.

\subsection{Operating envelope for stable coating process}

A rigorous simulation set was run, and the operating envelope was generated which is shown in Fig. 11. Flow rate below $0.9 \mathrm{ml} / \mathrm{h}$ and more than $1.75 \mathrm{ml} / \mathrm{h}$ was deemed unfit for the process. Based on these values, the substrate speed of $70 \mathrm{~mm} / \mathrm{s} \approx 100 \mathrm{~mm} / \mathrm{s}$ is the recommended substrate speed. Flow rate is the defining parameter in combination with the substrate speed. However, it is concluded that the coating process is more dependent on the flow rate.

\section{Experimental results}

Lab-made slot-die coating system used for the coating process is shown in Fig. 12. The coating system is connected with a roll-2-roll continuous manufacturing system which was delivering the flexible PET substrate at controlled speeds along with the ink where whole of the system was completely computer controlled. Films were deposited using the most suitable parameters i.e. $1.25 \mathrm{ml} / \mathrm{h}$ of flow rate and a substrate speed of $60 \mathrm{~mm} / \mathrm{s}$ while the stand-off distance was kept at $80 \mu \mathrm{m}$. These values were obtained by the simulation results as mentioned in the previous section. Films were sintered at $65^{\circ} \mathrm{C}$ for $45 \mathrm{~min}$ after the deposition process. Figure 13 represents the cross-sectional view of the scanning electron microscope (SEM) image of the achieved films while Fig. 14 represents the highly magnified image of the deposited films. Nicely uniform films with an average thickness of $\approx 3.5 \mu \mathrm{m}$ were obtained, thereby proving the validity of the operating envelope determined by the simulations. An error of $\approx 10 \%$ is acceptable between numerical and actual values $[11,12]$. Good particle integrity is 
observed, and particles are flocked together into agglomerates penetrating into each other. However, some pores are also observed which are present probably due to the low sintering temperature of the deposited films. This low sintering temperature condition is there because of PET substrate which has a glass transition temperature of $\approx 75^{\circ} \mathrm{C}$

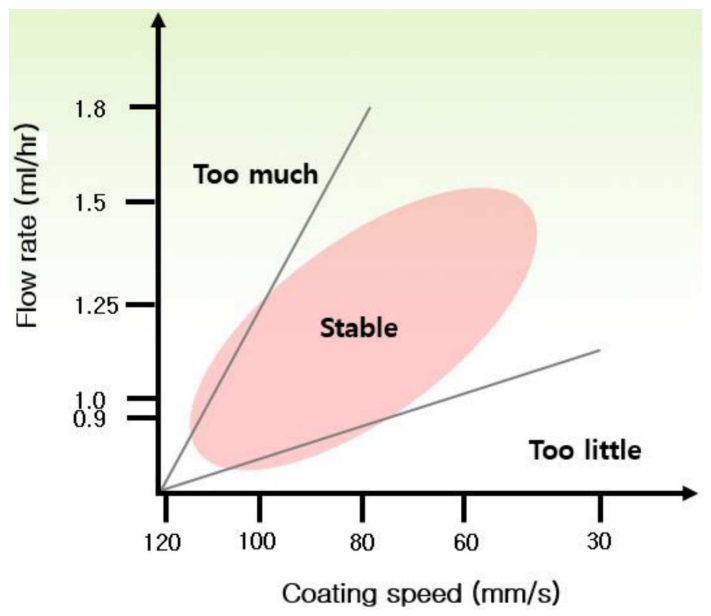

Fig. 11. Operating envelope for stable coating process.

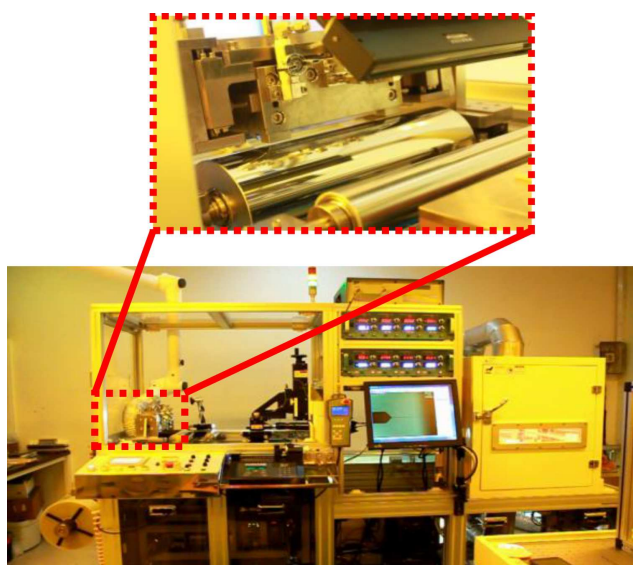

Fig. 12. Roll-to-roll slot die coating system.

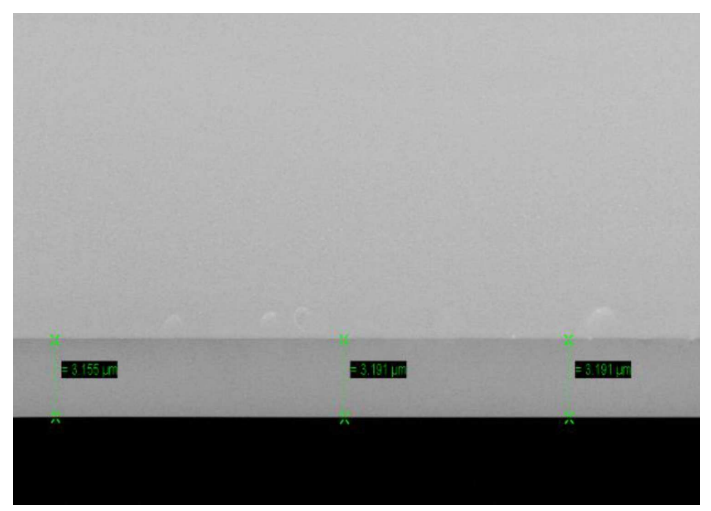

Fig. 13. Cross-sectional view of the films.

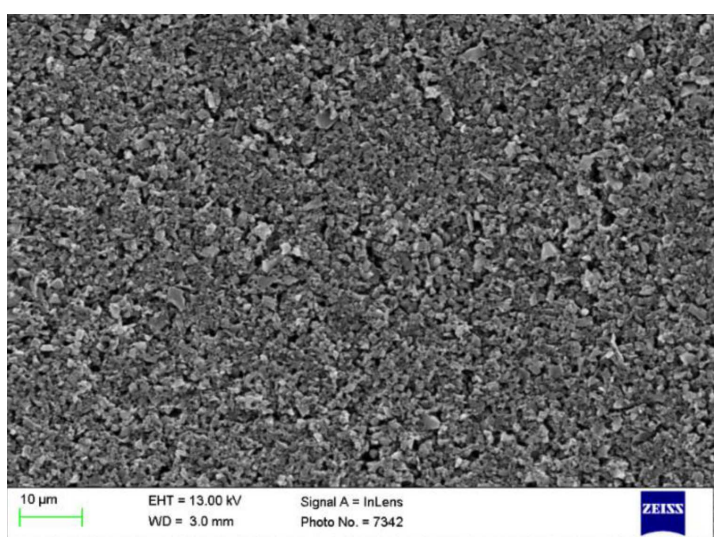

Fig. 14. SEM image of the deposited films showing excellent uniformity.

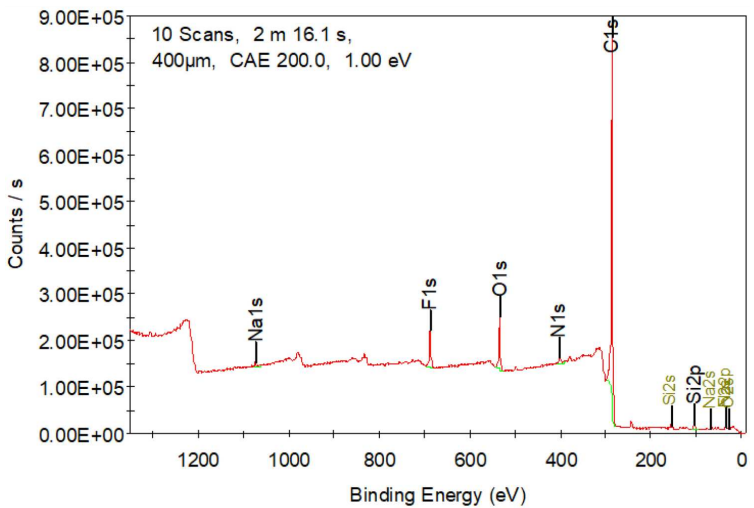

Fig. 15. XPS analysis representation of the deposited layers. Pure layers are identified with presence of trace amounts of impurities.

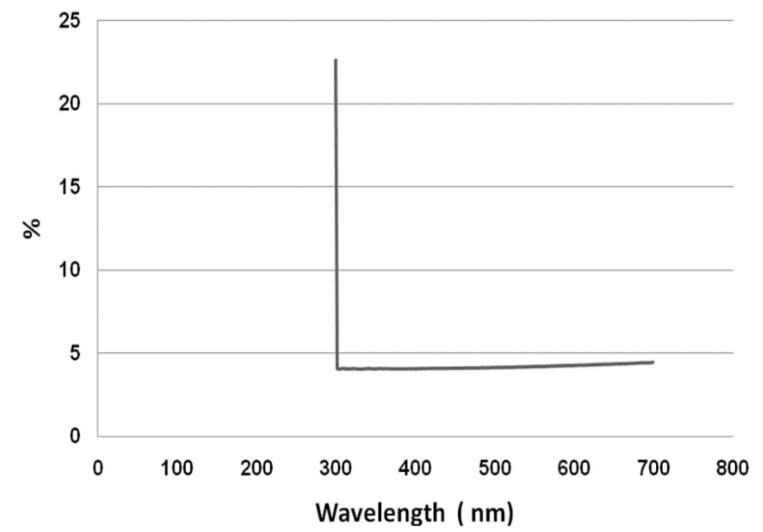

Fig. 16. Transmittance spectra of the deposited films with respect to wavelength $(\mathrm{nm})$ visible spectrum which confirms excellent absorbance characteristics of the films.

X-ray photoelectron analysis was carried out to confirm the chemical purity of the films and the results are depicted in Fig. 15. Layers with excellent purity are obtained with almost no impurities. Figure 16 shows 
the transmittance spectra of the deposited films against wavelength of the incident light and energy in visible spectrum. The layers exhibit excellent performance where the average transmittance is just around 5\%, showing the high level of uniformity of the films thereby absorbing almost all the incident light, which is very important for hydrogen storage applications as more condensed films would mean more surface area and hence better storage density.

\section{Conclusions}

Active carbon nanoparticle inks were used to produce high quality carbon films on flexible substrates via a direct deposition method, slot-die coating. Simulations were used a priori to determine the coating parameters i.e. flow rate and substrate speed. The simulations results matched with that of experiment results and $3 \mu \mathrm{m}$ thick films were achieved with excellent morphological, compositional, and absorbance characteristics. The deposited layers were ultra-pure and highly condensed. The characterizations results confirm the quality of the deposited films for their use in hydrogen storage applications. An added advantage of the process and the technique is that the layers were deposited through a high throughput non-vacuum continuous process. Therefore the proposed technique ensures cost-effectiveness as well as direct fabrication of the films.

\section{References}

[1] S.S. Mohammadshahi, E.M. Gray, C.J. Webb, Int. J. Hydrogen Energy 41, 3470 (2016).

[2] B. Panella, M. Hircher, Adv. Mater. 17, 538 (2005).

[3] Y. Jia, C. Sun, S. Shen, J. Zou, S.S. Mao, X. Yao, Renew. Sustain. Energy Rev. 44, 289 (2015).

[4] M.D. Tyona, Adv. Mater. Res. 2, 195 (2013).

[5] C.L. Mangun, M.A. Daley, R.D. Braatz, Carbon 36 123 (1998).

[6] J.M.V. Nabais, P.J.M. Carrott, M.M.L.R. Carrott, J.A. Menéndez, Carbon 42, 1315 (2004).

[7] K.H. Choi, N.M Muhammad, M.A.A. Rehmani, D.S. Kim, Proc. Inst. Mech. Eng. C J. Mech. Eng. Pract. 226, 842 (2012).

[8] K.H. Choi, A. Ali, A. Rahman, N.M. Mohammad, K. Rahman, A. Khan, S. Khan, D.S. Kim, J. Micromech. Microeng. 220, 075033 (2010).

[9] L. We, N. Nitta, G. Yushin, ACS Nano 7, 6498 (2013).

[10] M. Fathy, T.A. Moghny, M.A. Mousa, A.H.A.A. ElBellihi, A.A. Awadallah, Arab. J. Sci. Eng. 42, 225 (2017).

[11] K. Ali, K.H. Choi, N.M. Muhammad, Chem. Vap. Deposit. 17, 537 (2016).

[12] A. Bellingham, N. Bromhead, A. Fontecchio, Materials 10, 594 (2017).

[13] X. Ding, T.F. Fuller, T.A.L. Harris, J. Coat. Technol. Res. 11, 83 (2014). 